\title{
Chronic Exposure to Cold Stress Alters Electrophysiological Properties of Locus Coeruleus Neurons Recorded In Vitro
}

\author{
Hank P Jedema*,1 and Anthony A Grace ${ }^{1,2}$ \\ 'Department of Neuroscience; ${ }^{2}$ Department of Psychiatry, University of Pittsburgh, Pittsburgh, PA, USA
}

\begin{abstract}
Chronic stress exposure can alter central noradrenergic function. Previously, we reported that in chronically cold-exposed rats the release of norepinephrine and electrophysiological activation of locus coeruleus (LC) neurons is enhanced in response to multiple excitatory stimuli without alterations in basal activity. In the present studies, we used in vitro intracellular recording techniques to explore the effect of chronic cold exposure on the basal and evoked electrophysiological properties of LC neurons in horizontal slices of the rat brainstem. Consistent with our findings from in vivo experiments, chronic cold exposure did not affect basal firing rate. Furthermore, gross morphology of LC neurons and spike waveform characteristics were similar in slices from control and previously cold-exposed rats. However, excitability in response to intracellular current injection and input resistance were larger in slices from previously cold-exposed rats. In addition, the accommodation of spike firing in response to sustained current injection was smaller and the period of postactivation inhibition appeared to be less in LC neurons from cold-exposed rats. These data demonstrate that the stress-evoked sensitization of LC neurons observed in vivo is at least in part maintained in the slice preparation and suggest that alterations in electrophysiological properties of LC neurons contribute to the chronic stress-induced sensitization of central noradrenergic function observed in vivo. Furthermore, the present data suggest that an alteration in autoinhibitory control of LC activity is involved in the chronic stress-induced alterations. The enhanced functional capacity of LC neurons following cold exposure of rats may represent a unique model to study the mechanisms underlying the alterations in central noradrenergic function observed in humans afflicted with mood and anxiety disorders. Neuropsychopharmacology (2003) 28, 63-72. doi: I0.1038/sj.npp. 1300020
\end{abstract}

Keywords: electrophysiology; locus coeruleus; norepinephrine; chronic cold stress; tyrosine hydroxylase; stress-induced sensitization

\section{INTRODUCTION}

The neurons of the locus coeruleus (LC), tightly clustered at the floor of the fourth ventricle, provide the major source of norepinephrine (NE) in the central nervous system via their projections throughout the entire neuraxis (Foote et al, 1983; Moore and Card, 1984). NE released from LC neurons is thought to play an important role in attention and arousal (Robbins, 1984; Aston-Jones et al, 1999; Berridge, 2001), and alterations in central noradrenergic function have been implicated in the pathophysiology of multiple mood and anxiety disorders (Charney et al, 1990, 1995; Aston-Jones et al, 1994; Bremner et al, 1996; Wong et al, 2000).

The noradrenergic system is postulated to play a primary role in an organism's response to stress (Stanford, 1995). Thus, it is well established that acute stress exposure can increase the discharge activity and NE release from noradrenergic LC neurons (Korf et al, 1973; Abercrombie and Jacobs, 1987; Abercrombie et al, 1988). Furthermore,

\footnotetext{
*Correspondence: HP Jedema, Department of Neuroscience, University of Pittsburgh, 446 Crawford Hall, Pittsburgh, PA 15260, USA. E-mail: Jedema@bns.pitt.edu
}

Received 9 February 2002; revised 9 May 2002; accepted I July 2002 chronic exposure to stress can alter the response of LC neurons to subsequent stress exposure (for reviews see Stanford, 1993, 1995; Zigmond et al, 1995). For example, the activity of the rate-limiting enzyme in the synthesis of NE, tyrosine hydroxylase (TH), is increased in the LC following chronic exposure to cold, social stress, social isolation, or repeated exposure to restraint or foot shock (Zigmond et al, 1974; Stone et al, 1978; Angulo et al, 1991; Nisenbaum et al, 1991; Watanabe et al, 1995; Rusnak et al, 1998). Furthermore, the stress-evoked turnover of $\mathrm{NE}$ is enhanced following repeated exposure to foot shock or restraint (Thierry et al, 1968; Irwin et al, 1986; Adell et al, 1988; Anisman and Zacharko, 1990), and the evoked increase in LC spike firing is enhanced following chronic exposure to cold, repeated exposure to foot or tail shock but not to white noise (Simson and Weiss, 1988; Curtis et al, 1995; Conti and Foote, 1996; Mana and Grace, 1997; Jedema et al, 2001). We have focused on cold exposure as a chronic stressor because the alterations in central noradrenergic function that occur in rats following chronic cold exposure resemble those observed in humans afflicted with mood and anxiety disorders (Aston-Jones et al, 1994; Charney et al, 1995; Wong et al, 2000). Thus, in addition to the alterations in TH (Zigmond et al, 1974; Nisenbaum et al, 1991; Melia 
et al, 1992) and evoked LC spike firing (Mana and Grace, 1997; Jedema et al, 2001) described above, chronic exposure to cold also increases the evoked release of $\mathrm{NE}$ from nerve terminals in the hippocampus or medial prefrontal cortex (mPFC) (Nisenbaum et al, 1991; Gresch et al, 1994; Finlay et al, 1997; Jedema et al, 1999), and the increased responsivity of the LC noradrenergic system persists for many days following removal from the cold (Ramsooksingh et al, 2001). We have referred to this phenomenon as stressinduced sensitization of NE neurons.

Given that sciatic nerve stimulation activates LC neurons via a mechanism mediated by excitatory amino acids (Ennis et al, 1992) and is not mediated by CRH (Valentino et al, 1991), we hypothesized that either: (i) cold exposure leads to sensitization of multiple pathways that activate LC neurons or (ii) that the LC neurons themselves are more responsive to excitatory input, in general, following chronic cold exposure (Jedema et al, 2001). If the sensitized response occurs at the level of the LC neuron itself, then the enhanced responsiveness could be maintained in the in vitro brain slice preparation.

The present experiments used intracellular recording techniques to examine whether the sensitization of $\mathrm{NE}$ neurons observed previously in vivo is also present in vitro in brainstem slices containing the LC. Specifically, we examined both basal electrophysiological properties and excitability of LC neurons in slices obtained from control rats and rats previously exposed to cold. In addition, we compared the morphology of the recorded neurons from both groups.

\section{METHODS}

\section{Animals}

Male Sprague-Dawley rats (Hilltop, Scottdale, PA) weighing $50-100 \mathrm{~g}$ at the time of arrival were housed singly in hanging stainless-steel cages in a colony room maintained at an ambient temperature of $23^{\circ} \mathrm{C}$. Throughout the experiments, lights were maintained on a $12 \mathrm{~h}$ light/dark cycle (lights on at $08.00 \mathrm{am}$ ), with food (Laboratory rodent diet 5001, PMI Feeds, St Louis, MO) and water available ad libitum. All rats were housed in the colony room for 5-10 days prior to any treatment. All protocols were approved by the Institutional Animal Care and Use Committee at the University of Pittsburgh and were in accordance with the USPHS Guide for the Care and Use of Laboratory Animals.

\section{Cold Exposure}

Rats (135-200 g) were randomly assigned to a control or a cold-exposed group. Control rats were housed singly in hanging stainless-steel cages in a colony room maintained at an ambient temperature of $23^{\circ} \mathrm{C}$ for 2 weeks. The effects of chronic cold exposure on adrenal TH are more profound in shaved than unshaved rats (Fluharty et al, 1983) despite adequate thermal homeostasis (Moore et al, 2001). Therefore, the body fur of rats in the cold exposure group was shaved from the rump to the forelimbs immediately prior to cold exposure. These rats were housed singly in hanging stainless steel cages in a cold room maintained at an ambient temperature of $5^{\circ} \mathrm{C}$, where they remained undis- turbed for 2 weeks. Cold-exposed rats were removed from the cold room the afternoon prior to the experiment and housed overnight in a colony room maintained at an ambient temperature of $23^{\circ} \mathrm{C}$, thereby maintaining a protocol similar to that used previously for studying stress-induced sensitization of NE neurons (Nisenbaum et al, 1991; Gresch et al, 1994; Finlay et al, 1997; Mana and Grace, 1997; Jedema et al, 2001).

\section{Tissue Preparation}

Rats (190-300 g) were anesthetized with chloral hydrate $(400 \mathrm{mg} / \mathrm{kg}$, i.p.) and perfused through the ascending aorta with an ice-cold, oxygenated (low Na/high sucrose) perfusion solution $\left(1.9 \mathrm{mM} \mathrm{KCl}, 1.2 \mathrm{mM} \mathrm{Na} \mathrm{HPO}_{4}, 6 \mathrm{mM} \mathrm{MgCl} 2\right.$, $33 \mathrm{mM} \mathrm{NaHCO}_{3}, 20 \mathrm{mM}$ glucose, $229 \mathrm{mM}$ sucrose saturated with $95 \% \mathrm{O}_{2} / 5 \% \mathrm{CO}_{2}$ ) (Aghajanian and Rasmussen, 1989). Following decapitation, the brain was rapidly removed, placed in cold perfusion solution and $300 \mu \mathrm{m}$ thick horizontal slices containing the LC were prepared using a DSK Microslicer (Ted Pella). Tissue was transferred to cold, oxygenated aCSF (124 mM NaCl, $5 \mathrm{mM} \mathrm{KCl,} 1.2 \mathrm{mM}$ $\mathrm{KH}_{2} \mathrm{PO}_{4}, 2.4 \mathrm{mM} \mathrm{CaCl}, 1.3 \mathrm{mM} \mathrm{MgSO}_{4}, 26 \mathrm{mM} \mathrm{NaHCO}$, $10 \mathrm{mM}$ glucose saturated with $95 \% \mathrm{O}_{2} / 5 \% \mathrm{CO}_{2}$ ) (Lavin and Grace, 1998). After a recovery period of a minimum of 60 $90 \mathrm{~min}$, sections were transferred to the recording chamber where they were superfused with oxygenated aCSF at a flow rate of $0.8-1.5 \mathrm{ml} / \mathrm{min}$ at $35^{\circ} \mathrm{C}$.

\section{Electrophysiology}

Intracellular recordings were obtained from neurons in the LC that were tentatively identified by their location within the trans-illuminated slice. Electrodes were filled with biocytin ( $2 \%$ biocytin in $\left.2-3 \mathrm{M} \mathrm{KC}_{2} \mathrm{H}_{3} \mathrm{O}_{2}\right)$ and had an impedance of approximately 50-100 M $\Omega$. Putative LC neurons were identified based on a regular pattern of lowfrequency discharge of long-duration action potentials, as described in previous studies (Andrade et al, 1983; Williams et al, 1984; Ivanov and Aston-Jones, 1995). Input resistance was determined from current-voltage relationships using hyperpolarizing current steps $(0.02-0.4 \mathrm{nA}, 200 \mathrm{~ms}, 0.2 \mathrm{~Hz})$. Following recording of basal activity for 3-10 min, small depolarizing current pulses $(0.05-0.4 \mathrm{nA}, 500 \mathrm{~ms}, 0.5 \mathrm{~Hz}$, four current steps at each intensity with different intensities delivered at 20-30s intervals) were applied through the recording electrode in order to examine the neuronal excitability. At the end of each recording session, biocytin was ejected into the recorded cell for histological verification. Only one neuron per slice was examined.

\section{Immunocytochemistry}

Sections were stored in $4 \%$ paraformaldehyde or $10 \%$ buffered formalin solution for a minimum of 1 week. Sections were rinsed several times in phosphate buffer (PB: $0.1 \mathrm{M}, \mathrm{pH} 7.2-7.4$ ) or tris-buffered saline solution (TBS: $0.1 \mathrm{M}, \mathrm{pH}$ 7.6) before and between the following steps. Following a freeze-thaw procedure using decreasing concentrations of cryoprotectant and overnight incubation in a $1 \%$ Triton X-100 in TBS solution, tissue sections were incubated in avidin-biotin peroxidase complex (ABC; 1:200; 
Vectastain Elite kit; Vector Laboratories) in TBS. The peroxidase reaction was visualized by incubating the sections in $0.022 \%$ diaminobenzidine (DAB), $0.3 \%$ $\mathrm{NiSO}_{4}\left(\mathrm{NH}_{4}\right)_{2} \mathrm{SO}_{4}$ and $0.003 \%$ hydrogen peroxide in TBS for $6-7 \mathrm{~min}$. The peroxidase reaction was terminated by several rinses in TBS. Subsequently, the tissue was processed for $\mathrm{TH}$ immunoreactivity. Following incubation for $30 \mathrm{~min}$ in blocking solution (BS) containing 3\% normal goat serum, $0.4 \%$ Triton $\mathrm{X}-100$ and $1 \%$ bovine serum albumin in TBS, pH 7.6, sections were incubated overnight in $\mathrm{BS}$ containing a monoclonal antibody raised in mouse against TH (1:10 000; Chemicon). Following rinses in TBS tissue was incubated in secondary antibody (1:400; BA2001, Vector Laboratories) in BS for $30 \mathrm{~min}$, rinsed in TBS and incubated in $\mathrm{ABC}$. The peroxidase reaction was visualized by incubation in $0.022 \% \mathrm{DAB}$ and $0.003 \%$ hydrogen peroxide in TBS for $\sim 5 \mathrm{~min}$. Finally, sections were mounted on gelatin-coated glass slides, dehydrated through increasing concentrations of alcohols followed by xylene, and coverslipped, before verification that the location of the recorded neuron was indeed within the LC.

\section{Data Analysis}

Stable basal activity of LC neurons was recorded for a minimum period of $3 \mathrm{~min}$. Data for all action potentials for each individual neuron were averaged over the baseline period, and these values for each neuron were averaged for each treatment group. Firing rate (FR) was expressed as the average number of spikes discharged per second. The average membrane potential was estimated from the reading of the $V_{\mathrm{m}}$ displayed on the amplifier within the first $30 \mathrm{~s}$ of the penetration of the neuron. The action potential threshold was defined as the potential at which the greatest change in slope of the membrane potential occurred, which was determined from the second-order derivative of the membrane potential waveform. The amplitude of the action potential and afterhyperpolarization (AHP) were measured relative to this threshold, and the action potential duration was measured at the level of threshold. Statistical comparison of all parameters of basal activity between LC neurons from control and cold-exposed rats was performed using a $t$-test for independent samples. The excitability of LC neurons in response to current injection was defined as the differential of the FR occurring during a depolarizing current step and the basal FR for a specific neuron. Statistical comparison was performed by GreenhouseGeisser corrected ANOVA using group as factor and current intensity as a repeated measure. We expressed accommodation as the differential of the increase in instantaneous firing (reciprocal of interspike intervals (ISI)) above basal FR between the first two and last two action potentials during the train evoked by depolarizing current injection in order to account for any confounding effect due to differences in basal FR. The duration of the postactivation inhibition (PAI) was expressed as the ISI between the last action potential during and the first action potential following a $0.4 \mathrm{nA}$ current step. Statistical comparison of accommodation and PAI were performed using a $t$-test for independent samples. All statistical comparisons were performed using SPSS for Windows v10.1 (Chicago, IL) and the $\alpha$-level was set to 0.05 .

\section{RESULTS}

\section{Morphology of LC Neurons}

Recordings were made from 66 spontaneously active neurons from 29 control and 17 cold-exposed rats. The majority of these neurons (44 out of 66) was filled with biocytin following the recording session and subsequently processed for double labeling immunocytochemistry against biocytin and TH. In all cases in which a cell was filled with biocytin, it was surrounded by $\mathrm{TH}$-immunoreactive somata and processes (Figure 1) demonstrating that the recorded neuron was indeed within the LC. The morphology of the biocytin-immunoreactive neurons was consistent with that of identified LC neurons based on previous anatomical studies (Swanson, 1976; Groves and Wilson, 1980; Cintra et al, 1982) as well as that of LC neurons stained intracellularly in in vivo or in vitro preparations (Aghajanian and Vandermaelen, 1982a,b; Travagli et al, 1996; Jedema and Grace, 1999): a disc-shaped or multipolar soma with 4-9 processes emanating from its outer edge. There were no gross morphological differences between LC neurons from previously cold-exposed rats and control rats. LC neurons in slices from control rats had an average soma size of $26 \pm 1 \mu \mathrm{m}$ with an average of $5.7 \pm 0.2$ primary dendrites emanating from its perimeter $(n=33)$, while LC neurons in slices from cold-exposed rats had an average soma size of $25 \pm 2 \mu \mathrm{m}$ with an average of $5.6 \pm 0.4$ primary dendrites emanating from its perimeter $(n=11)$.

\section{Basal Discharge Activity}

The spontaneous discharge frequency of LC neurons in slices from control and cold-exposed rats was not significantly different $(2.15 \pm 0.19$ vs $2.81 \pm 0.55 \mathrm{~Hz}$; $n=43$ and 23 , respectively). There were no differences in any of the action potential waveform characteristics between slices from control and cold-exposed rats (see Table 1). No spontaneous postsynaptic potentials (excitatory or inhibitory) were observed.

\section{Hyperpolarizing Current Injection}

Hyperpolarizing current injection (duration 200-300 ms) through the recording electrode resulted in an amplitudedependent deflection of the steady-state membrane potential (Figure 2). Neurons from both cold-exposed and control rats exhibited inward rectification of the conductance, which is characteristic for LC neurons (Williams et al, 1984). The current-evoked steady-state membrane potential deflection was greater in LC neurons from cold-exposed rats $(\mathrm{F}(1,304)=9.101, \quad p=0.007)$ compared to control rats (Figure 3). The difference in membrane potential deflection between cold-exposed and control neurons varied linearly with the intensity of current injection in the range tested $(-0.5$ to $0.0 \mathrm{nA})$. The input resistance as determined from the instantaneous slope of the steady-state current-voltage relationship was greater in neurons from cold-exposed rats compared to control rats $(\mathrm{F}(1,304)=4.948, p=0.038)$, and this effect was independent of the amplitude of the current injection (Figure 3). 


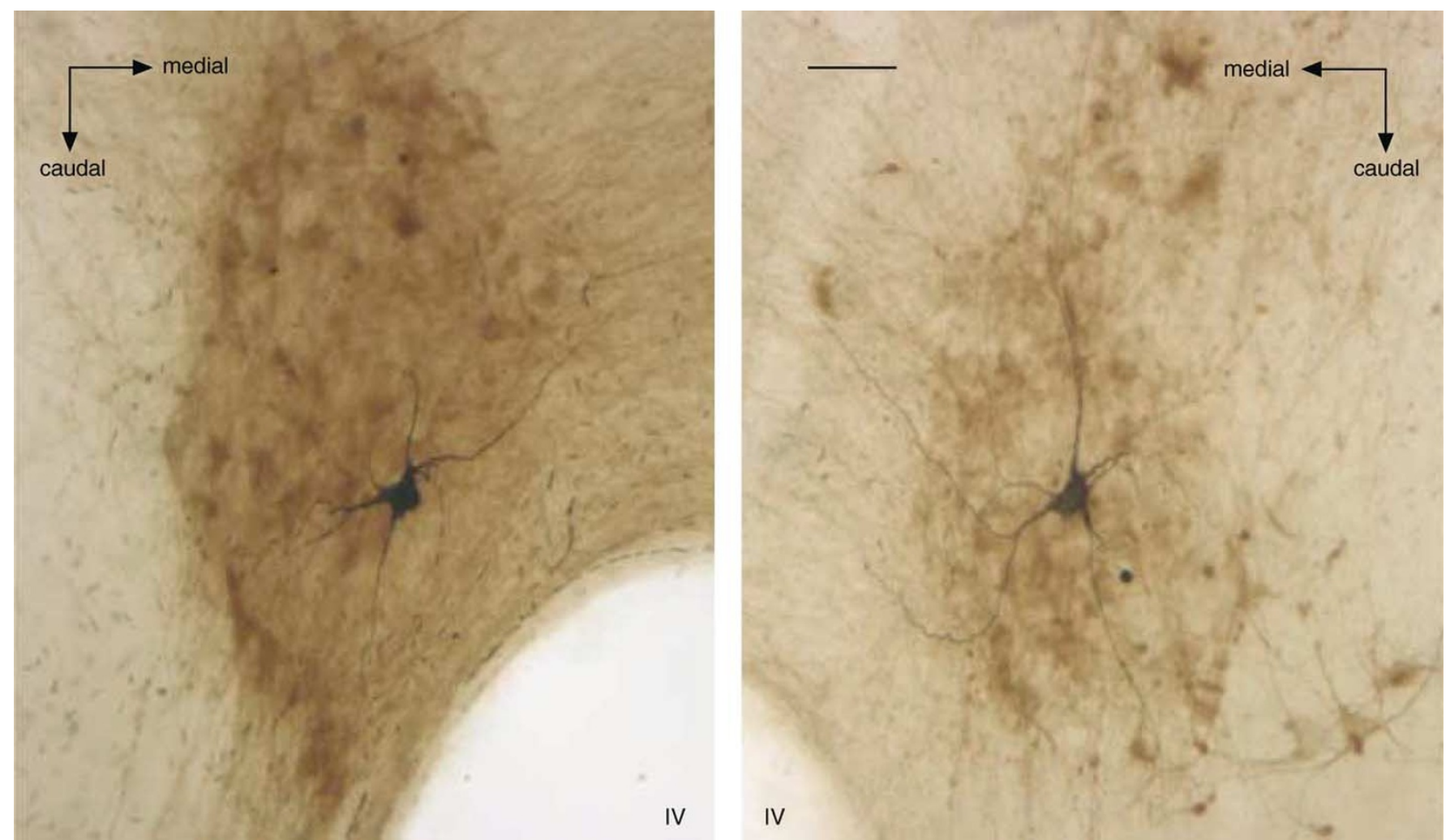

Figure I Identification and morphology of LC neurons recorded in vitro. Left: a representative example of an LC neuron filled with biocytin (black) in a horizontal brainstem slice obtained from a control rat. Immunoreactivity for tyrosine hydroxylase (brown) outlines the area of the locus coeruleus. Representative examples of LC neurons from a control (left) and cold-exposed rat (right) demonstrate that $L C$ neurons from control and cold-exposed rats have a similar morphology. LC neurons in slices from control rats had an average soma size of $26 \pm 1 \mu \mathrm{m}$ with an average of $5.7 \pm 0.2$ primary dendrites emanating from its perimeter $(n=33)$, while LC neurons in slices from cold-exposed rats had an average soma size of $25 \pm 2 \mu \mathrm{m}$ with an average of $5.6 \pm 0.4$ primary dendrites emanating from its perimeter $(n=1 \mathrm{I})$. Scale bar represents $50 \mu \mathrm{m}$ for both photomicrographs.

Table I Action Potential Waveform Characteristics ( \pm SEM) for Spontaneous Action Potentials in LC Neurons in Slices Obtained from Control and Previously Cold-Exposed Rats

\begin{tabular}{lrr}
\hline & Control & \multicolumn{1}{c}{ Cold } \\
\hline Resting membrane potential $(\mathrm{mV})$ & $-58.2 \pm 2.0$ & $-56.0 \pm 1.4$ \\
Action potential threshold $(\mathrm{mV})$ & $-49.4 \pm 2.5$ & $-50.2 \pm 1.9$ \\
Action potential amplitude $(\mathrm{mV})$ & $73.2 \pm 2.0$ & $75.3 \pm 1.3$ \\
Afterhyperpolarization $(\mathrm{mV})$ & $19.0 \pm 0.6$ & $20.1 \pm 0.9$ \\
Action potential duration $(\mathrm{ms})$ & $2.2 \pm 0.1$ & $2.1 \pm 0.1$ \\
\hline
\end{tabular}

( $n=14$ for each group); no between-group differences were observed

\section{Depolarizing Current Injection}

In response to intracellular depolarizing current injection (duration $500 \mathrm{~ms}$ ), an amplitude-dependent increase in the discharge activity above basal activity was observed, with larger current steps eliciting larger increases in discharge activity for neurons from both control and previously coldexposed rats (Figure 4). Neurons from cold-exposed rats showed a progressively larger increase in activation compared to neurons from control rats as evidenced by a significant group by current interaction $(\mathrm{F}(7,44)=3.849$, $p=0.044)$.

When sufficient depolarizing current was injected through the electrode, multiple spikes could be elicited with progressively longer interspike intervals (ISI); a process referred to as accommodation. The distribution of spikes during a current step, adjusted to evoke the same number of spikes above baseline, was different between neurons from cold-exposed and control rats. Specifically, when spike trains elicited by current steps adjusted to evoke six spikes were compared, the accommodation was significantly less in neurons from cold-exposed rats compared to control rats (Figure 5). Thus, neurons from cold-exposed rats exhibited a smaller decrease in instantaneous FR above baseline (inverse of ISI minus basal FR) during the current step compared to neurons obtained from control rats. The instantaneous FR above baseline for the last spike pair during the current step was $49 \pm 2 \%$ of that for the first spike pair in neurons from cold-exposed rats $v s$ $44 \pm 1 \%$ in control rats $(t(36)=2.328 ; p=0.026)$ (Figure 6). The postactivation inhibition, or time necessary to resume firing following a depolarizing current step eliciting the same number of spikes, appeared to be shorter in neurons from cold-exposed rats compared to those from controls 
a

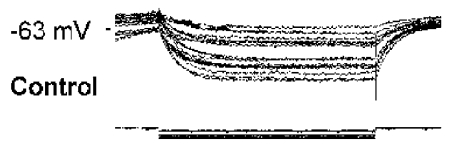

b

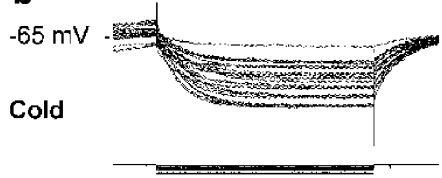

C

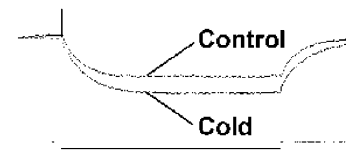

$25 \mathrm{msec} 10 \mathrm{mV} / 0.1 \mathrm{nA}$ d

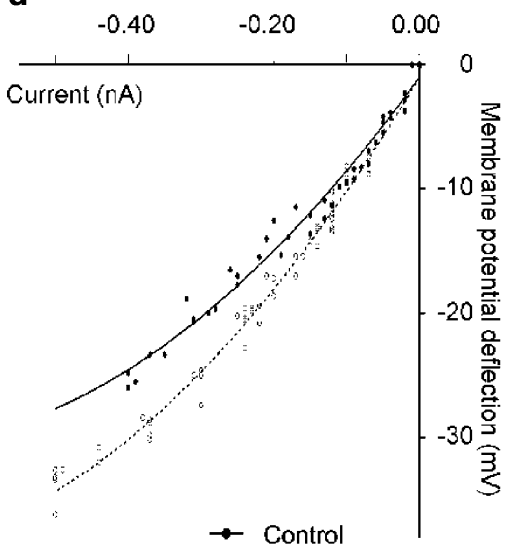

-0 - Cold

Figure 2 Current-voltage relationship of LC neurons from a control rat and a cold-exposed rat. Hyperpolarizing current steps (0-0.5 nA, $200 \mathrm{ms)}$ delivered through the recording electrode caused a deflection of the membrane potential in LC neurons from a control rat (a) and a cold-exposed rat (b). (c) Overlay of traces from a neuron of a control rat and a cold-exposed rat shows the larger deflection in the neuron of the cold-exposed rat. The values plotted in the current-voltage plot (d) were acquired at membrane steady state, which was more than I 25 ms following the initiation of the current pulse. The steady-state deflection of the membrane potential varied with the amplitude of current injection in a nonlinear manner, indicative of inward rectification. The slope resistances at the zero-current level calculated from the (quadratic) regression line were $8 \mathrm{I}$ and $98 \mathrm{M} \Omega$ for the control and cold-exposed rat, respectively.

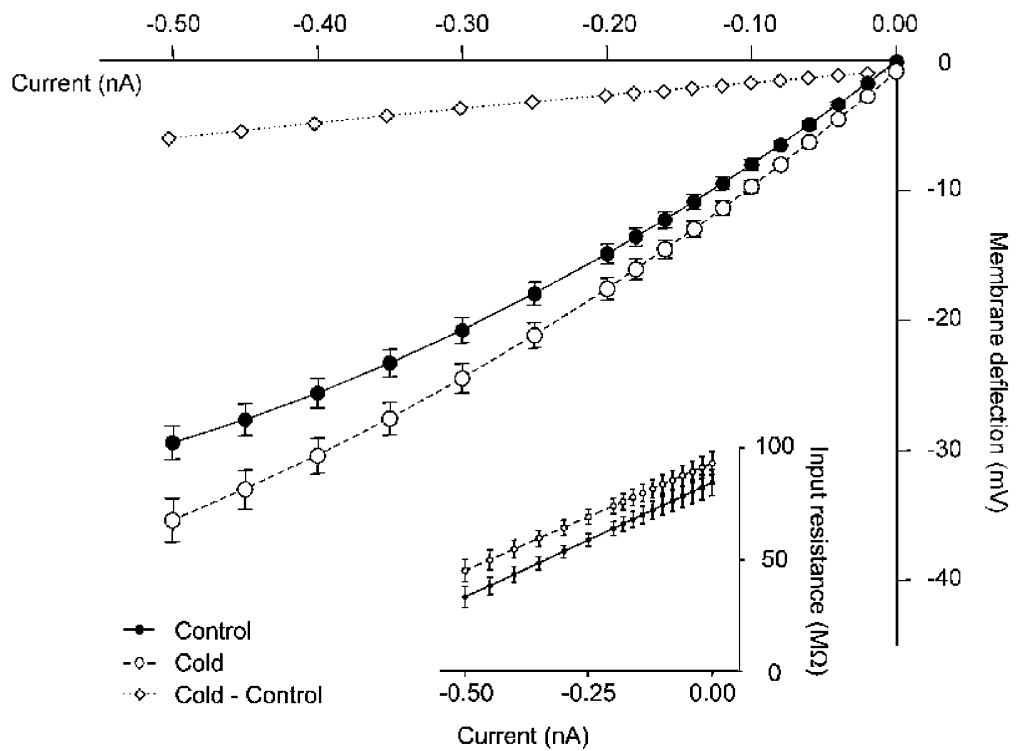

Figure 3 Input resistance of LC neurons from control and cold-exposed rats. Plotting the amplitude of hyperpolarizing current steps (200-300 ms) against the resultant steady-state deflection of the membrane potential for all neurons revealed that LC neurons from cold-exposed rats exhibit a larger deflection than control rats. The difference in voltage deflection between cold-exposed and control rats varies with the amplitude of current injection in a linear manner. Inset: the slope resistance of neurons of cold-exposed rats is larger compared to control. The average slope resistance at the zero-current level is $84 \pm 6$ and $93 \pm 5 M \Omega$ for control $(n=12)$ and cold-exposed rats $(n=9)$, respectively.

$(2227 \pm 359 \mathrm{~ms}$ vs $3151 \pm 360 \mathrm{~ms} ; n=16$ and 20 , respectively; Figure 6); however, this difference was not significant $(p=0.069)$ because of the large between-subject variation within both treatment groups.

\section{DISCUSSION}

The present data demonstrate that, following chronic coldexposure, LC neurons recorded in vitro exhibit an increased excitability without major alterations in basal FR. These data extend those of previous in vivo experiments demonstrating stress-induced sensitization of NE neurons (Nisenbaum et al, 1991; Gresch et al, 1994; Finlay et al, 1997; Mana and Grace, 1997; Jedema et al, 1999, 2001). The fact that an increased excitability without alteration of basal activity is found in the present in vitro experiments, in which presynaptic input does not play a significant role, supports the hypothesis that the sensitization of $\mathrm{NE}$ neurons observed in vivo is, at least in part, mediated by 


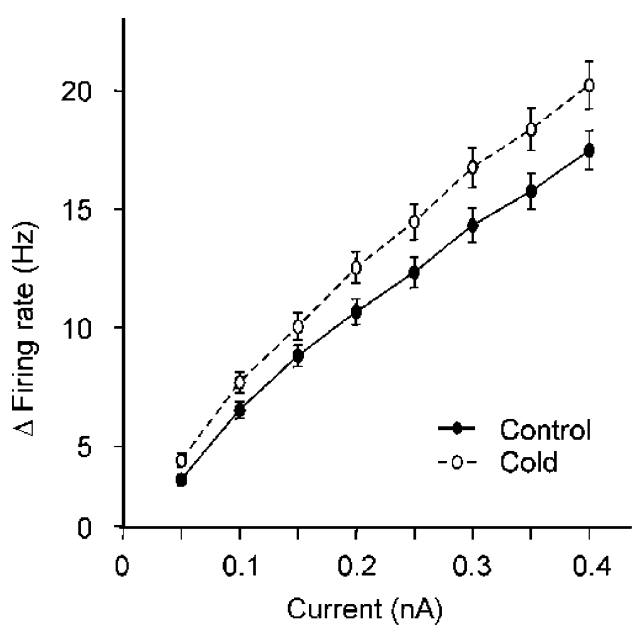

Figure 4 Excitability of LC neurons from control and cold-exposed rats. In response to an intracellular depolarizing current step $(500 \mathrm{~ms}), \mathrm{LC}$ neurons from cold-exposed rats exhibited a larger increase in FR above baseline compared to control rats $(F(7,44)=3.849, p=0.044 ; n=20$ and 26 , respectively).
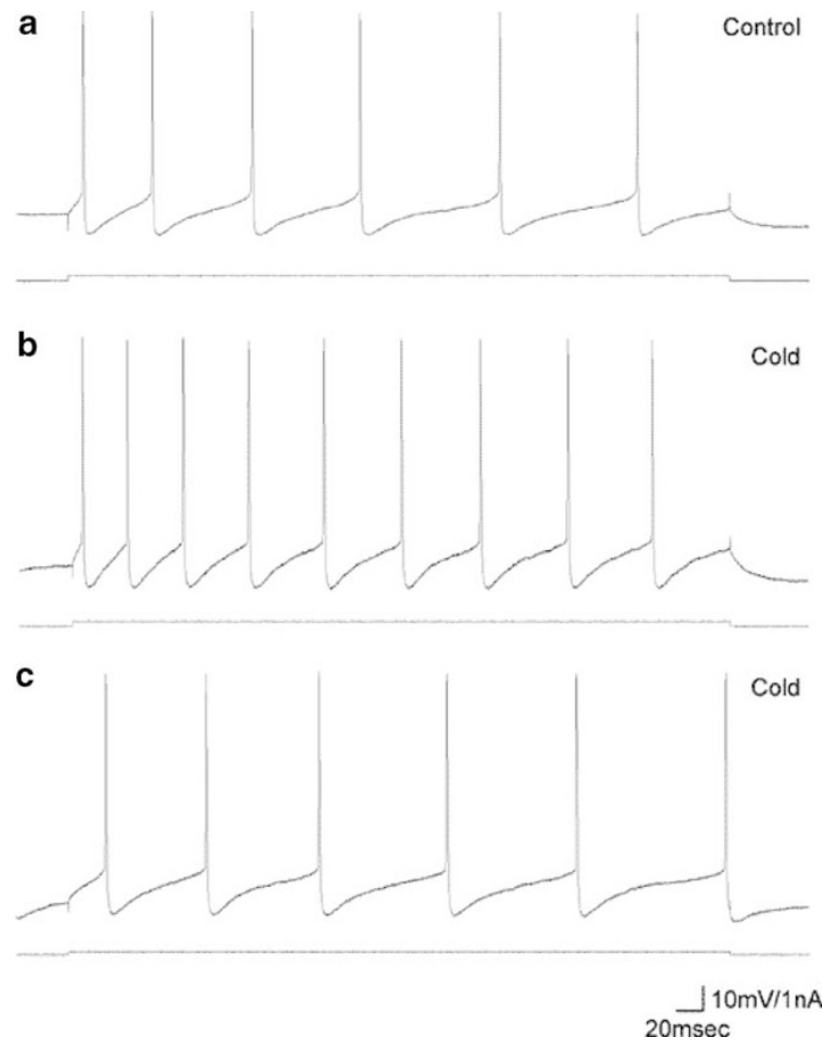

Figure 5 Example of trains of action potentials of LC neurons from control and cold-exposed rats evoked by sustained depolarizing current injection. In response to an intracellular depolarizing current step of equal amplitude $(0.2 n A)$, LC neurons from cold-exposed rats (b) discharged more action potential than control neurons (a). When the amplitude of current injection was adjusted to achieve the same level of excitation (ie the same number of action potentials), the neurons from the cold-exposed rat (c) exhibit less accommodation of spike firing than neurons from control rats. Basal FRs were 2.5 and $2.6 \mathrm{~Hz}$ for the neurons from the control and cold-exposed rat, respectively. an alteration of the LC neurons themselves (Jedema et al, 2001).

\section{Chronic Cold Exposure}

Chronic cold exposure, as used in the present study, is a complex stressor consisting of shaving, relocation to another room, return to a room at room temperature prior to testing, etc. We feel that the cold exposure itself is the most likely cause for the alterations in central noradrenergic function that is studied. Thus, we demonstrated that shaving followed by intermittent cold exposure or continuous cold exposure for only 1 week does not result in sensitization of NE release or electrophysiological activity of LC neurons (Finlay et al, 1997; Mana and Grace, 1997; Jedema et al, 1999), suggesting that neither shaving, room changes nor removal from the cold room are responsible for the sensitization of NE neurons. Nevertheless, the possibility exists that an interaction of cold exposure and other factors is required to cause sensitization of LC neurons.

\section{Basal Discharge Activity}

The basal discharge activity of LC neurons in slices from both control and previously cold-exposed rats is similar to that observed in our in vivo experiments (Mana and Grace, 1997; Jedema et al, 2001). In addition, the values obtained for basal LC activity in slices from control rats were consistent with previously reported values from other in vitro experiments (Andrade et al, 1983; Williams et al, 1984; Ivanov and Aston-Jones, 1995). Furthermore, the action potential waveform characteristics of spontaneously occurring action potentials of LC neurons from both control and cold-exposed rats were similar to each other and they were completely consistent with those reported previously (Andrade et al, 1983; Williams et al, 1984; Travagli et al, 1996).

\section{Hyperpolarizing Current Injection}

The amplitude of the steady-state membrane potential deflection produced in response to hyperpolarizing current injection increased with the current injection amplitude in a nonlinear manner, which could be well described by a quadratic function. LC neurons show a clear inward rectification as previously described (Williams et al, 1984, 1988). This rectification is thought to be a result of the inward rectifying properties of potassium conductances (Williams et al, 1984, 1988; Grigg et al, 1996). The input resistance in control slices was lower than the majority of previously published findings. However, it should be noted that in the present study brainstem slices were used that were sectioned in the horizontal plane. It has been reported that the plane in which slices are sectioned greatly influences the number of remaining dendrites and the input resistance of LC neurons (Travagli et al, 1996), with horizontal sections allowing the greatest preservation of the dendritic arbor. Indeed, the input resistance obtained in the present study in horizontal slices of control rats is similar to the values for LC neurons in horizontal slices estimated from the publication by Travagli et al (1996). In addition, the input resistance in our slice experiments more closely 

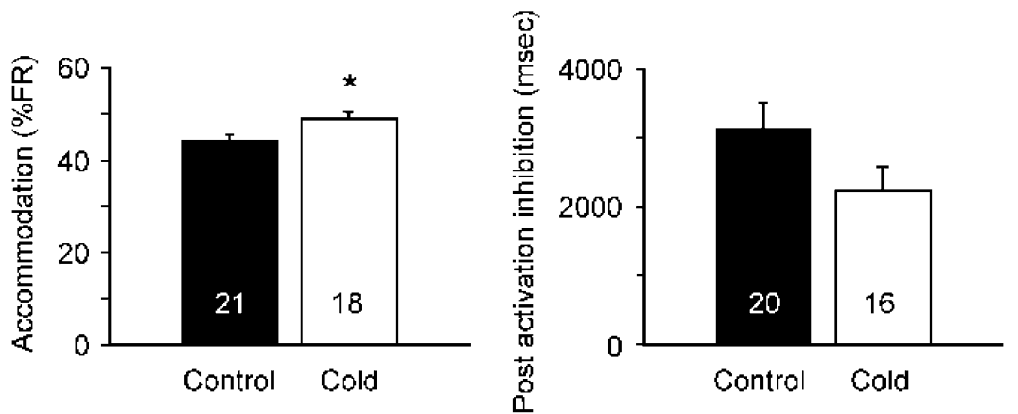

Figure 6 Evoked spike train characteristics of LC neurons from control and cold-exposed rats. Left: in response to a depolarization of the membrane, LC neurons discharged trains of action potentials that exhibited accommodation, which is observed as a decrease in instantaneous FR above baseline from the first to the last spike during a current step (expressed as a percentage of initial instantaneous FR). LC neurons in slices from control rats showed a larger decrease in instantaneous FR: instantaneous FR at the last spike over the first spike in control neurons was significantly less compared to neurons from coldexposed rats. Right: LC neurons typically show a postactivation period of inhibition. The duration of inhibition appeared shorter in neurons from coldexposed rats, although this difference was not statistically significant as a result of large between-subjects variation within groups.

approximates previous findings for input resistance of LC neurons obtained in vivo (Aghajanian and VanderMaelen, 1982a; Jedema and Grace, 1999).

The membrane potential deflection produced in neurons from cold-exposed rats was significantly greater when compared to control rats. This difference in membrane potential deflection varied linearly with the amplitude of current injection, which would suggest that a change in nonrectifying conductances underlies the observed difference between neurons from cold-exposed and control rats. Although the amplitude of hyperpolarization did not extend into the voltage range where inward rectification is most prominent (Williams et al, 1988), inward rectification was evident in the present recordings in both control and coldexposed preparations (ie Figures 2 and 3). The difference in input resistance between LC neurons from control and coldexposed rats was independent of the amplitude of the hyperpolarizing current injected throughout the range of hyperpolarizing current steps tested, further indicating that the difference between neurons from cold-exposed and control rats was not caused by alteration of conductances exhibiting rectification in the voltage range tested.

\section{Depolarizing Current Injection}

A higher level of excitability was observed in LC neurons obtained from cold-exposed rats when compared to control rats, which was most apparent with larger amplitudes of depolarization. This was likely due, at least in part, to a change in membrane conductance since the input resistance of LC neurons from cold-exposed rats was greater compared to control rats. The fact that higher amplitudes of current injection will evoke a greater number of action potentials, in combination with an increase in the input resistance, suggests that a decrease in potassium or chloride conductances is involved in the mechanism underlying the enhanced excitability that we have observed in neurons from chronically stressed rats. The chloride conductance evoked by GABA administration, however, is known to exhibit a strong outward rectification (Osmanovic and Shefner, 1990), suggesting that this conductance is not responsible for the observed differences between neurons from cold-exposed and control rats.
In addition to an increase in excitability, LC neurons from cold-exposed rats exhibited a smaller decrease in instantaneous FR over baseline (ie less accommodation) during a $500 \mathrm{~ms}$ 'burst' evoked by depolarizing current injection. Nonetheless, there was no significant difference in the amplitude of the AHP between control and cold-exposed groups. Differences in AHP duration, on the other hand, were difficult to evaluate in spontaneously active LC cells, because the membrane potential increases in a continuous manner from the AHP into the depolarizing ramp that precedes the next action potential discharge. Even though only voltage clamp recordings will enable us to resolve which currents are altered by chronic cold exposure, one potential alteration that could contribute to a change in AHP duration could be the apamin-sensitive calciumactivated potassium conductance that plays an important role during the middle phase of the AHP as well as in the accommodation observed in LC neurons (Osmanovic et al, 1990; Osmanovic and Shefner, 1993). Apamin was reported to cause these changes in AHP and accommodation without changing the spontaneous FR or membrane potential of the majority of the LC neurons (Osmanovic et al, 1990). In a few cases, we tested the excitability of control neurons during bath application of apamin and observed an increase in excitability similar to what we observed in neurons of coldexposed rats (Jedema and Grace, unpublished observations). Even though a reduction in a calcium-activated potassium conductance may potentially account for the increase in excitability, it is unlikely that this would explain the increased membrane potential deflection in response to hyperpolarizing current, given the requirement for calcium influx.

Alterations in autoreceptor function following chronic stress exposure that might result in changes in autoinhibition have been described in vivo (Pavcovich et al, 1990; Pavcovich and Ramirez, 1991; Nisenbaum and Abercrombie, 1993; Flugge, 2000). Alpha-2 receptor activation causes a G-protein-mediated hyperpolarization of LC neurons via the opening of potassium channels (Aghajanian and Vandermaelen, 1982a; Williams et al, 1985; Arima et al, 1998). This hyperpolarization is accompanied by a decrease of the input resistance, and the current-voltage relationship of this conductance is fairly linear (Williams et al, 1985). 
However, the role for $\alpha$-adrenergic autoreceptors in the auto-inhibition of LC neurons in vitro is controversial (Andrade and Aghajanian, 1984; Ivanov and Aston-Jones, 1995), and it is unclear to what extent the basal activity of LC neurons in vitro is influenced by tonic $\alpha_{2}$-receptor activation. Regardless, whether it is an $\alpha_{2}$-receptor effect on potassium conductances or a calcium-activated potassium conductance, an alteration in autoinhibition is a likely candidate that may contribute to the differences we have observed in vitro between LC neurons from control and cold-exposed rats. It remains to be determined whether the difference in excitability observed in the present experiments can completely account for the enhanced excitability observed in our in vivo experiments, or whether alterations in LC afferent input also play a role. Additional alterations to afferent input are suggested by recent in vivo studies from our laboratory demonstrating a prolonged or secondary excitation in addition to an enhanced excitation of LC neurons in cold-exposed rats in response to sciatic nerve stimulation (Mana and Grace, 1997; Ramsooksingh et al, 2001).

In summary, the present studies demonstrate an enhanced evoked activity of LC neurons following chronic cold exposure. Studies in humans have implicated an enhanced central noradrenergic activity in mood and anxiety disorders (Charney et al, 1990, 1995; Aston-Jones et al, 1994; Bremner et al, 1996; Wong et al, 2000). Given the proposed role for central $\mathrm{NE}$ in arousal and attention (Robbins, 1984; Aston-Jones et al, 1999; Berridge, 2001), an enhanced central noradrenergic activation could underlie the increased response to stress observed in post-traumatic stress disorder or the increased distractibility reported for attention-deficit hyperactivity disorder (ADHD). Given other parallels between mood and anxiety disorders in humans and alterations in rats following cold exposure, the paradigm of continuous cold exposure and the resultant sensitization of LC neuron responses may represent a unique experimental model to study potential mechanisms involved in the alterations underlying these disorders. The fact that the changes in excitability occur in vitro, largely in the absence of synaptic input, suggests that alterations integral to the LC neurons themselves underlie the enhanced noradrenergic function in cold-exposed rats, and perhaps could contribute to the altered central noradrenergic function in mood or anxiety disorders observed in humans.

\section{ACKNOWLEDGMENTS}

We thank Christy Smolak and Meera Ramsooksingh for expert technical assistance and Brian Lowry for Neuroscope data analysis software.

\section{REFERENCES}

Abercrombie ED, Jacobs BL (1987). Single-unit response of noradrenergic neurons in the locus coeruleus of freely moving cats I Acutely presented stressful and nonstressful stimuli. $J$ Neurosci 7: 2837-2843.
Abercrombie ED, Keller Jr RW, Zigmond MJ (1988). Characterization of hippocampal norepinephrine release as measured by microdialysis perfusion: pharmacological and behavioral studies. Neuroscience 27: 897-904.

Adell A, Garcia-Marquez C, Armario A, Gelpi E (1988). Chronic stress increases serotonin and noradrenaline in rat brain and sensitizes their responses to a further acute stress. J Neurochem 50: $1678-1681$.

Aghajanian GK, VanderMaelen CP (1982a). Alpha 2-adrenoceptormediated hyperpolarization of locus coeruleus neurons: intracellular studies in vivo. Science 215: 1394-1396.

Aghajanian GK, Vandermaelen CP (1982b). Intracellular identification of central noradrenergic and serotonergic neurons by a new double labeling procedure. J Neurosci 2: 1786-1792.

Aghajanian GK, Rasmussen K (1989). Intracellular studies in the facial nucleus illustrating a simple new method for obtaining viable motoneurons in adult rat brain slices. Synapse 3: 331-338.

Andrade R, Aghajanian GK (1984). Locus coeruleus activity in vitro: intrinsic regulation by a calcium-dependent potassium conductance but not alpha 2-adrenoceptors. J Neurosci 4: 161170.

Andrade R, Vandermaelen CP, Aghajanian GK (1983). Morphine tolerance and dependence in the locus coeruleus: single cell studies in brain slices. Eur J Pharmacol 91: 161-169.

Angulo JA, Printz D, Ledoux M, McEwen BS (1991). Isolation stress increases tyrosine hydroxylase mRNA in the locus coeruleus and midbrain and decreases proenkephalin mRNA in the striatum and nucleus accumbens. Brain Res Mol Brain Res 11: 301-308.

Anisman H, Zacharko RM (1990). Multiple neurochemical and behavioral consequences of stressors: implications for depression. Pharmacol Therapeutics 46: 119-136.

Arima J, Kubo C, Ishibashi H, Akaike N (1998). Alpha2adrenoceptor-mediated potassium currents in acutely dissociated rat locus coeruleus neurones. J Physiol 508: 57-66.

Aston-Jones G, Rajkowski J, Cohen J (1999). Role of locus coeruleus in attention and behavioral flexibility. Biol Psychiatry 46: $1309-1320$

Aston-Jones G, Valentino RJ, Van Bockstaele EJ, Meyerson AT (1994). Locus coeruleus, stress, and PTSD: neurobiological and clinical parallels. In: Murburg MM (ed). Catecholamine Function in PTSD: Emerging Concepts. American Psychiatric Press: Washington, DC, pp 17-62.

Berridge CW (2001). Arousal and attention-related actions of the locus coeruleus-noradrenergic system: potential target in the therapeutic actions of amphetamine-like stimulants. In: Solanto MV, Arnsten AFT, Castellanos FX (eds). Stimulant Drugs and $A D H D$. Oxford University Press: New York, pp 158-184.

Bremner JD, Krystal JH, Southwick SM, Charney DS (1996). Noradrenergic mechanisms in stress and anxiety: II. Clinical studies. Synapse 23: 39-51.

Charney DS, Bremner JD, Redmond DE Jr (1995). Noradrenergic neural substrates for anxiety and fear. In: Bloom FE, Kupfer DJ (eds). Psychopharmacology: The Fourth Generation of Progress. Raven Press Ltd: New York, pp 387-395.

Charney DS, Woods SW, Nagy LM, Southwick SM, Krystal JH, Heninger GR (1990). Noradrenergic function in panic disorder. $J$ Clin Psychiatry 51: 5-11.

Cintra L, Diaz-Cintra S, Kemper T, Morgane PJ (1982). Nucleus locus coeruleus: a morphometric Golgi study in rats of three age groups. Brain Res 247: 17-28.

Conti LH, Foote SL (1996). Reciprocal cross-desensitization of locus coeruleus electrophysiological responsivity to corticotropin-releasing factor and stress. Brain Res 722: 19-29.

Curtis AL, Pavcovich LA, Grigoriadis DE, Valentino RJ (1995). Previous stress alters corticotropin-releasing factor neurotransmission in the locus coeruleus. Neuroscience 65: 541-550. 
Ennis M, Aston-Jones G, Shiekhattar R (1992). Activation of locus coeruleus neurons by nucleus paragigantocellularis or noxious sensory stimulation is mediated by intracoerulear excitatory amino acid neurotransmission. Brain Res 598: 185-195.

Finlay JM, Jedema HP, Rabinovic AD, Mana MJ, Zigmond MJ, Sved AF (1997). Impact of corticotropin-releasing hormone on extracellular norepinephrine in prefrontal cortex after chronic cold stress. J Neurochem 69: 144-150.

Flugge G (2000). Regulation of monoamine receptors in the brain: dynamic changes during stress. Int Rev Cytol 195: 145-213.

Fluharty SJ, Snyder GL, Stricker EM, Zigmond MJ (1983). Shortand long-term changes in adrenal tyrosine hydroxylase activity during insulin-induced hypoglycemia and cold stress. Brain Res 267: 384-387.

Foote SL, Bloom FE, Aston-Jones G (1983). Nucleus locus ceruleus: new evidence of anatomical and physiological specificity. Physiol Rev 63: 844-914.

Gresch PJ, Sved AF, Zigmond MJ, Finlay JM (1994). Stress-induced sensitization of dopamine and norepinephrine efflux in medial prefrontal cortex of the rat. J Neurochem 63: 575-583.

Grigg JJ, Kozasa T, Nakajima Y, Nakajima S (1996). Single-channel properties of a G-protein-coupled inward rectifier potassium channel in brain neurons. J Neurophysiol 75: 318-328.

Groves PM, Wilson CJ (1980). Fine structure of rat locus coeruleus. J Comp Neurol 193: 841-852.

Irwin J, Ahluwalia P, Anisman H (1986). Sensitization of norepinephrine activity following acute and chronic footshock. Brain Res 379: 98-103.

Ivanov A, Aston-Jones G (1995). Extranuclear dendrites of locus coeruleus neurons: activation by glutamate and modulation of activity by alpha adrenoceptors. J Neurophysiol 74: 2427-2436.

Jedema HP, Grace AA (1999). Morphology of individual noradrenergic neurons of the locus coeruleus following in vivo intracellular recording. Soc Neurosci Abstr 25: 1208.

Jedema HP, Sved AF, Zigmond MJ, Finlay JM (1999). Sensitization of norepinephrine release in medial prefrontal cortex: effect of different chronic stress protocols. Brain Res 830: 211-217.

Jedema HP, Finlay JM, Sved AF, Grace AA (2001). Chronic cold exposure potentiates $\mathrm{CRH}$-evoked increases in electrophysiologic activity of locus coeruleus neurons. Biol Psychiatry 49: 351359.

Korf J, Aghajanian GK, Roth RH (1973). Increased turnover of norepinephrine in the rat cerebral cortex during stress: role of the locus coeruleus. Neuropharmacology 12: 933-938.

Lavin A, Grace AA (1998). Dopamine modulates the responsivity of mediodorsal thalamic cells recorded in vitro. J Neurosci 18: 10566-10578.

Mana MJ, Grace AA (1997). Chronic cold stress alters the basal and evoked electrophysiological activity of rat locus coeruleus neurons. Neuroscience 81: 1055-1064.

Melia KR, Rasmussen K, Terwilliger RZ, Haycock JW, Nestler EJ, Duman RS (1992). Coordinate regulation of the cyclic AMP system with firing rate and expression of tyrosine hydroxylase in the rat locus coeruleus: effects of chronic stress and drug treatments. J Neurochem 58: 494-502.

Moore RY, Card JP (1984). Noradrenaline-containing neuron systems. In: Björklund A, Hökfelt T (eds). Handbook of Chemical Neuroanantomy, Vol. 2: Classical Transmitters in the CNS, Part I. Elsevier: Amsterdam, pp 123-156.

Moore H, Rose HJ, Grace AA (2001). Chronic cold stress reduces the spontaneous activity of ventral tegmental dopamine neurons. Neuropsychopharmacology 24: 410-419.

Nisenbaum LK, Abercrombie ED (1993). Presynaptic alterations associated with enhancement of evoked release and synthesis of norepinephrine in hippocampus of chronically cold-stressed rats. Brain Res 608: 280-287.

Nisenbaum LK, Zigmond MJ, Sved AF, Abercrombie ED (1991). Prior exposure to chronic stress results in enhanced synthesis and release of hippocampal norepinephrine in response to a novel stressor. J Neurosci 11: 1478-1484.

Osmanovic SS, Shefner SA (1990). Gamma-aminobutyric acid responses in rat locus coeruleus neurones in vitro : a currentclamp and voltage-clamp study. J Physiol 421: 151-170.

Osmanovic SS, Shefner SA (1993). Calcium-activated hyperpolarizations in rat locus coeruleus neurons in vitro. J Physiol 469: 89-109.

Osmanovic SS, Shefner SA, Brodie MS (1990). Functional significance of the apamin-sensitive conductance in rat locus coeruleus neurons. Brain Res 530: 283-289.

Pavcovich LA, Ramirez OA (1991). Time course effects of uncontrollable stress in locus coeruleus neuronal activity. Brain Res Bull 26: 17-21.

Pavcovich LA, Cancela LM, Volosin M, Molina VA, Ramirez OA (1990). Chronic stress-induced changes in locus coeruleus neuronal activity. Brain Res Bull 24: 293-296.

Ramsooksingh MD, Jedema HP, Moore H, Sved AF, Grace AA (2001). The effects of chronic stress on the regulation of locus coeruleus neurons by peripheral, limbic, and prefrontal cortical inputs. Soc Neurosci Abstr 27: 738-739.

Robbins TW (1984). Cortical noradrenaline, attention and arousal. Psychol Med 14: 13-21.

Rusnak M, Zorad S, Buckendahl P, Sabban EL, Kvetnansky R (1998). Tyrosine hydroxylase mRNA levels in locus ceruleus of rats during adaptation to long-term immobilization stress exposure. Mol Chem Neuropathol 33: 249-258.

Simson PE, Weiss JM (1988). Altered activity of the locus coeruleus in an animal model of depression. Neuropsychopharmacology 1 : 287-295.

Stanford SC (1993). Monoamines in response and adaptation to stress. In: Stanford SC, Salmon P (eds). Stress: from synapse to syndrome. Academic Press: New York, pp 281-331.

Stanford SC (1995). Central noradrenergic neurones and stress. Pharmacol Therapeutics 68: 297-242.

Stone EA, Freedman LS, Morgano LE (1978). Brain and adrenal tyrosine hydroxylase activity after chronic footshock stress. Pharmacol, Biochem Behav 9: 551-553.

Swanson LW (1976). The locus coeruleus: a cytoarchitectonic, Golgi and immunohistochemical study in the albino rat. Brain Res 110: 39-56.

Thierry AM, Javoy F, Glowinski J, Kety SS (1968). Effects of stress on the metabolism of norepinephrine, dopamine and serotonin in the central nervous system of the rat. I. Modifications of norepinephrine turnover. J Pharmacol Exp Therapeutics 163: 163-171.

Travagli RA, Wessendorf M, Williams JT (1996). Dendritic arbor of locus coeruleus neurons contributes to opioid inhibition. $J$ Neurophysiol 75: 2029-2035.

Valentino RJ, Page ME, Curtis AL (1991). Activation of noradrenergic locus coeruleus neurons by hemodynamic stress is due to local release of corticotropin-releasing factor. Brain Res 555: 25-34.

Watanabe Y, McKittrick CR, Blanchard DC, Blanchard RJ, McEwen BS, Sakai RR (1995). Effects of chronic social stress on tyrosine hydroxylase mRNA and protein levels. Brain Res Mol Brain Res 32: $176-180$.

Williams JT, Henderson G, North RA (1985). Characterization of alpha 2-adrenoceptors which increase potassium conductance in rat locus coeruleus neurones. Neuroscience 14: 95-101.

Williams JT, North RA, Tokimasa T (1988). Inward rectification of resting and opiate-activated potassium currents in rat locus coeruleus neurons. J Neurosci 8: 4299-4306.

Williams JT, North RA, Shefner SA, Nishi S, Egan TM (1984). Membrane properties of rat locus coeruleus neurones. Neuroscience 13: 137-156.

Wong ML, Kling MA, Munson PJ, Listwak S, Licinio J, Prolo P et al (2000). Pronounced and sustained central hypernoradrenergic 
function in major depression with melancholic features: relation to hypercortisolism and corticotropin-releasing hormone. Proc Natl Acad Sci USA 97: 325-330.

Zigmond MJ, Finlay JM, Sved AF (1995). Neurochemical studies of central noradrenergic responses to acute and chronic stress. In: Friedman MJ, Charney DS, Deutsch AY (eds). Neurobiological

and Clinical Consequences of Stress: From Normal Adaptation to PTSD. Lippincott-Raven Publishers: Philadelpia, pp 45-60.

Zigmond RE, Schon F, Iversen LL (1974). Increased tyrosine hydroxylase activity in the locus coeruleus of rat brain stem after reserpine treatment and cold stress. Brain Res 70: 547-552. 